a comprehensive treatise. In general, the author seems to be most confident when dealing with laboratory conditions; he does not follow up his dissertation on water conductivity by explaining its correlation with the power demand and the extent of the effective fishing field or the relationship between anode and cathode sizes, which are all fundamental in practice.

To sum up, Dr. Denzer has written a useful book, which will save those interested a great deal of time spent in the study of useless papers, and although it cannot be regarded as complete, it is a distinct achievement to have compiled such an account, while its shortcomings are such that they may be excused in a pioneer.

W. G. Hartley

\section{NEANDERTHAL MAN}

\section{Les Néanderthaliens}

Anatomie, Physiologie, Comparaisons. Par Etienne Patte. Pp. 560. (Paris: Masson et $\mathrm{Cie}, 1955$. 5000 francs.

$\mathrm{N}$ the summer of last year an interesting con1 ference was held at Düsseldorf to celebrate the centenary of the discovery of the remains of Neanderthal man in a near-by cave. Although the conference received little attention in the scientific press, it was a worthy occasion in the history of palæoanthropology. For the discovery which it commemorated was the first which led to the recognition that physical types of humanity existed in the past which were very different from those which live in modern days. At the time of the original discovery in 1856, the Neanderthal skull aroused controversies which to-day seem to have been unnecessarily acrimonious, but then such controversies always do seem (and, because of the hidden emotions engendered, perhaps always will be) the fate of discoveries of early man or his progenitors. Since Neanderthal man came to light near Düsseldorf, many other remains of the same physical type have been found elsewhere, and together (in spite of local variations) they show a rather remarkable uniformity in their basic characters. Perhaps more has been written and speculated about Neanderthal man than any other Palæolithic type, and there is no reason to suppose that the last word on his origin and fate has yet been pronounced.

The publication of Dr. E. Patte's book in the centenary year of the Düsseldorf discovery is opportune, but it is disappointing that it adds nothing new, either in analysis of structural features or in their interpretation in terms of function and evolutionary relationships. It is, in fact, a compilation, and a far from complete one at that. But the author shows a welcome sense of proportion when he comes to deal with certain speculations which have in some textbooks gradually transformed themselves into statements of fact. He rightly discredits the rash inferences which from time to time have been made from a study of endocranial casts, and he finds no reason to accept the suggestion that Neanderthal man walked with a peculiar gait which is so often depicted in illustrations. Here he directs attention to the rather remarkable, but not uncommon, fallacy of comparing fossil skeletal remains only with the skeletal features of the European, with the underlying assumption that the latter can be accepted as a representative sample of modern man as a whole. But, as Dr. Patte remarks in reference to the subject of his monograph, "Il n'avait pas une démarche de Parisien, mais il n'y a pas que des Parisiens sur terre". It is curious that in his list of references the author does not include the important work of G. M. Morant or Clark Howell, for this (together with more recent studies, such as those of Fusté) has provided some of the most suggestive evidence for the theory that Neanderthal man, at any rate in the later stages of his evolutionary development, was a distinct and somewhat aberrant ramification of the genus Homo. Indeed, it is commonly accepted that he represents a separate species, Homo neanderthalensis. Whether this specific distinction is really warranted will probably only be determined with the accumulation of still more skeletal remains, but at least it gives expression to what even now seems reasonably certain, that the extreme type of Neanderthal man of later Palæolithic date was a divergent type which became extinct and had no ancestral relationship to Homo sapiens. W. E. ILE Gros Clark

\section{TECHNOLOGY OF THIN FILMS}

\section{Vacuum Deposition of Thin Films}

By L. Holland. Pp. xix $+542+25$ plates. (London : Chapman and Hall, Ltd., 1956.) 70s. net.

$\mathrm{N}$ his preface, the author remarks that in this book 1 he has attempted to fill the deficiency existing with regard to a survey of developments in the subject since 1946. After perusal, the reader will surely agree with Prof. S. Tolansky, who writes in the foreword that "As far as I know there is no other text which approaches this subject in so useful a technological manner. There are many papers, many articles, and much tradition. Here we have for the first time an admirable summary of all of this accumulated experience brought together by an experimenter only too familiar with the many pitfalls".

The author has a wealth of experience in the field of vacuum technique, a fact which is very evident from many personal comments he has interspersed on various topics throughout the text. The reader is assumed to have a basic grounding in high-vacuum procedure. As a consequence, this well-established branch of physics is discussed only when pertinent to evaporation and sputtering equipment.

The presentation of the large amount of material is conveniently classified under three main headings : evaporation in vacuo, cathodic sputtering, and the preparation of oxide films. A glance through the chapter titles shows how comprehensive is the treatment. The first five chapters deal with evaporation equipment, the degassing of plastic materials in vacuo, pre-evaporation cleaning, and the emission characteristics of various vapour sources and film thickness distribution. Evaporation techniques for alloy deposition are mentioned, followed by an interesting account of the growth and structure of vacuum-deposited films.

The ever-growing importance of thin films for electrical and optical applications makes the six chapters devoted to them especially welcome. Detailed descriptions are included of film thickness monitoring techniques for multilayer interference films and the control of the transmission wave-length 